\title{
Management of Steroid-dependency with Clofazimine [Lamprene or B 663 (Geigy)]
}

\author{
JUNE MORGAN \\ Christian Hospital, Monorom, Thailand
}

One of the main complications of leprosy confronting the clinician is the state known as reaction or acute exacerbation of the disease. Whether the patient presents in progressive lepra reaction or with repeated episodes of erythema nodosum leprosum (ENL), corticosteroids are often needed to control the symptoms. Indeed, high fever, severe peripheral neuritis, swollen and painful glands, or painful joints can often be controlled only by the use of these drugs. The danger is that such patients may become steroid-dependent. (Steroid dependence implies that the patients need to take rorticosteroids continuously to control their symptoms, and that cessation of such treatment is followed by recurrence of the symptoms.) The side-effects of prolonged treatment with these drugs or with ACTH (corticotrophin) have been clearly pointed out by Jopling (1962), West (1962), and others.

Another related problem, of course, is the control of active disease. All anti-leprosy drugs, even in very small doses, are liable to precipitate an episode of acute exacerbation. The patient's condition may steadily deteriorate in spite of his taking steroids, because he cannot tolerate any drug that would control the active disease. It has been reported that clofazimine (Lamprene or B 663 (Geigy)) has an antibacterial action as well as an anti-inflammatory action (Barry and Conalty, 1965; Browne, 1965, 1966; Imkamp, 1968).

In October, 1967, a supply of Lamprene (B 66:3) in 100-mg capsules was made available by courtesy of Messrs. Geigy S.A. Basle, and the first 7 patients were chosen to take part in a trial of the drug; since then, 23 patients have

\footnotetext{
*Accepted for publication September, 1970.
}

been treated with the drug at this hospital. Of these original 2:3 patients, one absconded but, being later persuaded to return for treatment, was brought into the trial again, another absconded and did not return, and one died, possibly of adrenal failure.

\section{CHOICE OF PATIENTS}

Patients for treatment with Lamprene were chosen for the following reasons: (1) Dependency on corticosteroids to control ENL or progressive lepra reaction [exacerbation nodules, or ENL, according to Ridley's classification of reactions (Ridley, 1969)]. (2) Inability to tolerate even small doses of anti-leprosy drugs, especially dapsone. Some patients had had full courses of other drugs, such as thiambutosine or thiosemicarbazone, but because of the danger of developing drug resistance it was considered unwise to continue giving these drugs. (3) The occurrence of severe peripheral neuritis, arthritis, or enlargement and suppuration of lymph nodes. (4) Increasing deformity. (5) A stationary or rising bacillary index (BI) and/or morphological index (MI). (These findings might imply the appearance of drug-resistance, but no steps were taken to verify this possibility.)

All but 2 of the 23 patients had been given corticosteroids at one time or another for short or long courses, and all such treatment had been given in hospital. One had received inadequate doses as an out-patient some years previously, before hospital facilities were available, while another had treated himself with corticosteroids and had been admitted to hospital as an emergency with steroid-induced haematemesis. Of the 23 patients in the trial, 14 were on frequent or almost continuous corticosteroid 
therapy when treatment with Lamprene was begun. In none of the patients was the dosage of anti-leprosy drugs sufficient to control the disease, 10 of them being in exacerbation of the progressive type of lepra reaction, and 12 liable to repeated episodes of ENL. The bacillary and morphological indices of 11 of the patients were either stationary or rising, and 4 had severe peripheral neuritis with increasing limb deformity.

\section{ADMINISTRATION OF STEROIDS}

Corticosteroids had been given by two methods: (1) short course starting with a daily dosage of $40 \mathrm{mg}$ of prednisolone, which was then reduced rapidly every other day, the total duration of the course being not more than 10 days; or (2) a longer course adjusted to the patient's symptoms. This longer course consisted of 30 to $40 \mathrm{mg}$ of prednisolone given on alternate days and gradually tapering off as the patient's symptoms improved. All steroid-dependent patients were on the alternate-day régime. Some patients were also receiving $\mathrm{ACTH}$, either in occasional doses of 40 units or once or twice weekly. At the beginning of the trial, the patients on prednisolone were receiving from 5 to $20 \mathrm{mg}$ of the drug daily. The 14 patients who were steroid-dependent when starting the treatment with Lamprene were weaned from steroids in periods varying between 2 weeks and 7 months.

\section{ADMINISTRATION OF LAMPRENE}

Lamprene was given in a starting dose of either $100 \mathrm{mg}$ on alternate days, or $100 \mathrm{mg}$ daily, the dosage being gradually increased every 2 or 3 weeks until there was a definite clinical response. At the same time, the dosage of prednisolone was progressively decreased. Most patients received a maximum dosage of $300 \mathrm{mg}$ of Lamprene daily, but some needed $400 \mathrm{mg}$ daily, and one as much as $600 \mathrm{mg}$ daily. When there was no further evidence of symptoms of reaction, and when the patient had been completely weaned from corticosteroids, the dosage of Lamprene was gradually reduced to a level that controlled the symptoms. Most patients were maintained on a daily dosage of $100 \mathrm{mg}$, some received $100 \mathrm{mg}$ on alternate days, but a few needed $200 \mathrm{mg}$ daily. When the patient's BI and MI had both fallen, dapsone was reintroduced in low doses, which were slowly increased at monthly intervals. Lamprene was stopped after a 6 -month overlap with dapsone. $\mathrm{Up}$ to the time of writing, these patients have remained free of complications since the reintroduction of dapsone; 4 patients of the original 23 are now back on dapsone therapy.

\section{CLINICAL RESPONSE}

Many of the patients showed an almost immediate amelioration of symptoms. After Lamprene was given, some improved dramatically and were soon well enough to do things they had been unable to do for years. But those who were steroid-dependent were often slower to respond; in these cases, the dosage of both Lamprene and steroids had to be carefully adjusted to the individual's needs. A few became worse for a brief period after being on Lamprene for 6 to 10 weeks, with in some cases a severe exacerbation of symptoms. But they would then suddenly begin to improve and thereafter make steady progress. An intercurrent infection during treatment could also precipitate an acute exacerbation, but the latter usually improved as appropriate treatment controlled the precipitating infection.

\section{BACTERIAL RESPONSE}

The Bacterial Index (BI) and Morphological Index (MI) were determined at the beginning of the trial, and thereafter every 3 months (not always by the same technician).

All patients showed a steady response to treatment, as far as the leprosy infection was concerned. Of the 16 patients who have completed one year's treatment with Lamprene, all had a raised BI at the beginning of the trial, and all but 4 had viable bacillary forms in the smears. At the end of a year, only 6 had a raised $\mathrm{BI}$ and none had viable forms in the smears. Of those who had been steroid- 
dependent, 6 still had a raised BI after one year, but in all of them the MI was zero.

\section{HAEMATOLOGICAL FINDINGS}

Some degree of anaemia was present in most of the patients before treatment with Lamprene, but as their general condition improved so also did their haemoglobin levels. Our aim was to raise the haemoglobin level to at least $75 \%$ $(11 \mathrm{~g})$. Malaria and hookworm infection were controlled by appropriate treatment.

A leukocyte count was made each month. Initial counts were all high, ranging from 15,000 to 30,000 per $\mathrm{mm}^{3}$. As the clinical picture improved, so the count gradually returned to normal. If an exacerbation occurred during treatment, it was found that the white cell count increased. During treatment, 7 of the patients showed a mild eosinophilia. In no case, however, did the count fall to an abnormally low level, and in all cases it was normal after 6 to 8 months' treatment. The urine of all the patients was examined weekly for protein, but none of them developed any kidney complications.

\section{SKIN PIGMENTATION}

No patient objected to the pigmentation of the skin that developed. All turned a deep red, and the lesions later became black. Even black lesions on the face did not seem to embarrass the patients. The wide range of skin colour among the population in Thailand may account for the ready acceptability of a change in skin pigmentation due to the drug. Out of the 21 patients still taking Lamprene, only one Chinese patient had difficulty with his family because of the change in his appearance.

All the patients were admitted to hospital at the beginning of treatment with Lamprene. When weaned from steroids, and as their health improved, they all asked to continue treatment as out-patients. This they were allowed to do; they returned to hospital each month for examination, some travelling considerable distances, well over $100 \mathrm{~km}$ (62 miles). They came by public transport, but pigmentation did not seem to constitute a social problem.

\section{DISCUSSION}

All 23 patients in this series treated with Lamprene responded well to treatment. After about 4 to 6 weeks, 12 patients had a further episode of acute exacerbation of their symptoms, but this yielded to an increase in the dosage of the drug. Once the patient began to improve, he usually made good and steady progress. Intermittent infections provoked an occasional episode of acute exacerbation, but this improved as the infection was controlled. Some patients needed a short course of steroids at this time.

Side-effects were minimal; 2 patients complained of nausea, and a few of itching of the skin. Pigmentation of the skin was obvious in all the patients, the normal skin turning brick red and the lesions black. But this did not prove to be a problem. Patients who had been steroiddependent were treated as out-patients once they had been weaned from dependence, and those who were not taking corticosteroids were given Lamprene as out-patients. The drug had no apparent effect on enlarged, painful, or suppurating lymph nodes.

In all the patients the BI and MI showed a steady improvement and normal bacilli disappeared rapidly from smears taken routinely. No kidney complications were seen. White cell counts, which were high $-20,000$ to 30,000 in most cases-fell steadily and remained between 7000 and 11,000 .

\section{CONCLUSION}

All patients in the series treated with Lamprene had severe complications of leprosy. Out of 2:3 patients, 14 were steroid-dependent when they started to take Lamprene. None had had adequate treatment with any antileprosy drug.

Treatment with Lamprene had the following results: (a) patients could be weaned from dependence on steroids; (b) the acute exacerbation was brought under control; (c) normal bacillary forms disappeared rapidly from routine smears, and the BI fell consistently; (d) peripheral neuritis was controlled; (e) return to dapsone treatment became possible, and 5 of the patients are now taking full doses of DDS. 
Both patients and staff were impressed with the efficacy of Lamprene. Apart from skin pigmentation (which as shown did not constitute a problem here), there were no sideeffects. For patients who are steroid-dependent, or who have intractable peripheral neuritis or persistent severe exacerbations, Lamprene is the drug of choice.

The author's results were subjected to statistical analysis, based on the 11 patients who completed the whole course of treatment, i.e. first with other anti-reactional drugs and then with clofazimine.

For each patient the following variables were used for the statistical evaluation, viz. the duration of the treatment period, the number of reactions occurring during the period, and the duration of such reactions. The two periods (i.e. before clofazimine treatment and during treatment with this drug) were then compared in 3 ways: the mean number of reactions in the 2 periods (number of reactions per month of the period); the mean duration of the reaction in the 2 periods; the relative duration of all reactions in the period according to the length of the period. Because of the low number of patients (1 I) completing the trial, parameter-free methods were considered appropriate for the statistical analysis.

It was demonstrated that: (1) reactions occurred less often during the period of clofazimine treatment; (2) the mean duration of each reaction was shorter during treatment with clofazimine; and (3) the total duration of reactions occurring in the clofazimine treatment period was less than during treatment with other anti-reactional drugs. It is pointed out that the 2 periods were not strictly balanced, clofazimine being given only in the later period, and also that results were available for only 11 of the 14 patients. Nevertheless, they are considered to be "an indication of the superiority of treatment" with clofazimine.

\section{ACKNOWLEDGEMENTS}

I wish to thank J. R. Geigy S.A., Basle, Switzerland, for their generous supply of Lamprene (B 663), and Dr. T. Ahrens and Dr. S. G. Browne, o.B.E., for their help, encouragement and advice during the trial.

I am also grateful to Dr. Maly of Messrs. Geigy for the statistical analysis of my results.

\section{REFERENCES}

BARRY, v. C. and Conalty, M. L. (1965). The antimycobacterial activity of B 663. Lepr. Rev. 36, 3.

BRowne, s. G. (1965). Treatment of leprosy with B 663. Appraisal of the pilot trial after 3 years. Lepr. Rev. 36, 13.

BRowne, S. G. (1966). B 663 (Geigy); further observations on its suspected anti-inflammatory action. Lepr. Rev. 37, 141 .

IMKAмP, F. M. J. H. (1968). A treatment of corticosteroid-dependent lepromatous patients in persistent ENL. A clinical evaluation of B 663. Lepr. Rev. 39, 119.

JOPLING, W. H. (1962). Treatment of erythema nodosum leprosum. In Leprosy in Theory and Practice, 2nd ed., p. 420. Bristol, John Wright and Sons.

RIDley, D. S. (1969). Reactions in leprosy. Lepr. Rev. 40, 77 .

WEST, H. F. (1962). General principles of corticosteroid therapy. In Leprosy in Theory and Praznideed., p. 405. Bristol, John Wright and Sons. 